\title{
PITYRIASIS LICHENOIDES - RELATO DE DOIS CASOS QUE EVIDENCIAM O VARIADO ESPECTRO DE APRESENTAÇÃO DESTA RARA DOENÇA
}

\author{
Alexandre Sabino Sisnando', Bárbara Agonio', Laryssa Madeira', Fabio Francesconi² \\ 'Médico residente em Dermatologia/Resident of Dermatology, Fundação de Medicina Tropical Heitor Vieira Dourado (FMT-HVD) \\ ${ }^{2}$ Dermatologista/Dermatologist, Mestre em doenças tropicais (pela FMT-HVD)/Specialist in tropical diseases, Preceptor da \\ residência médica em dermatologia (FMT-HVD)/Tutor of residency in dermatology, Professor da disciplina de dermatologia/Professor \\ of Dermatology, Faculdade de Medicina da Universidade Federal do Amazonas (FM-UFAM), Brasil
}

\begin{abstract}
RESUMO - Pityriasis lichenoides é uma dermatose rara, de etiologia desconhecida, cujo espectro de apresentações clínicas varia de uma forma aguda, a pityriasis lichenoides et varioliformis acuta (PLEVA) a uma forma mais insidiosa e recorrente, a pityriasis lichenoides chronica (PLC). A PLEVA, ou doença de Mucha-Habermann, tem um quadro abrupto de pápulas no tronco, nádegas e extremidades proximais que progridem rapidamente para vesículas ou formam crostas hemorrágicas, podendo deixar cicatrizes deprimidas. Já a PLC apresenta pequenas pápulas descamativas, assintomáticas ou pruriginosas, que podem se desenvolver ao longo de dias, também com distribuição ao tronco, nádegas e extremidades proximais. As lesões podem continuar surgindo e involuindo ao longo de meses, algumas vezes causando hipopigmentação pós-inflamatória. O doente não costuma evoluir de um polo de apresentação para outro, tendendo a cura espontânea ou após tratamento. Acredita-se que a pitiríase liquenóide seja uma reação de hipersensibilidade a agentes infecciosos diversos, com proliferação clonal autolimitada de células $T$, em que a resposta imunológica ao clone provoca as manifestações clínicas e histopatológicas. Já foi identificado rearranjo dos receptores do gene gama de células T (TCR-gama) por técnicas de PCR. O anatomopatológico mostra alterações típicas de cada forma de apresentação. $\bigcirc$ artigo apresenta dois casos bem representativos desta rara doença, evidenciando as principais características de cada um dos polos da pitiríase liquenóide. Ambos tiveram resolução com o uso de Doxiciclina.
\end{abstract}

PALAVRAS-CHAVE - Pitiríase liquenoide.

\section{PITYRIASIS LICHENOIDES - REPORT OF TWO CASES SHOWING THE WIDE SPECTRUM OF PRESENTATION OF THIS RARE DISEASE}

ABSTRACT - Pityriasis lichenoides is a rare skin disease of unknown etiology, whose spectrum of clinical presentation varies from an acute form, pityriasis lichenoides et varioliformis acuta (PLEVA) to a more insidious and recurrent one, pityriasis lichenoides chronica (PLC). PLEVA, or Mucha-Habermann disease, has an acute onset of papules on the trunk, buttocks and proximal extremities that rapidly progress to vesicles or form hemorrhagic crusts, and may leave depressed scars. PLC, by contrast, has small scaly papules, asymptomatic or pruritic, which can develop over days, on the same distribution. The lesions may continue appearing and disappearing over months, sometimes causing post-inflammatory hypopigmentation. The patient does not usually evolve from a clinical form to another, tending to spontaneous healing or the cure comes after treatment. It is believed that pityriasis lichenoides is a hypersensitivity reaction to various infectious agents and with self-limiting clonal proliferation of $T$ cells, wherein the immune response to the clone leads to clinical and pathological manifestations. It has been detected T-cell receptor gamma gene rearrangement (TCR-gamma) by PCR. Pathological exam shows typical changes of each presentation. This paper presents two very representative cases of this uncommon disease, showing the main features of each form of pityriasis lichenoides. Both had resolution with the use of Doxycycline.

KEY-WORDS - Pityriasis lichenoides.

Subsídios de bolsa de residência médica para o autor ${ }^{1}$ e co-autores ${ }^{1}$; Scholarships of residency granted to author ${ }^{7}$ and coauthors ${ }^{1}$.

Manuscrito apresentado parcialmente como pôster eletrônico no XX Congresso Ibero Latinoamericano de Dermatologia, no Rio de Janeiro, Brasil, de 15 a 18 de novembro de 2014 com o título; Presented as an electronic poster at the XX Congress 


\title{
Caso Clínico
}

\author{
Iberic Latin-American of Dermatology, Rio de Janeiro, Brazil, 15th to 18th November 2014. \\ Conflitos de interesse: Os autores declaram não possuir conflitos de interesse. No conflicts of interest. \\ Suporte financeiro: O presente trabalho não foi suportado por nenhum subsídio ou bolsa. No sponsorship or scholarship granted. \\ Direito à privacidade e consentimento escrito / Privacy policy and informed consent: Os autores declaram que pediram \\ consentimento ao doente para usar as imagens no artigo. The authors declare that the patient gave written informed consent for \\ the use of its photos in this article. \\ Recebido/Received - Fevereiro/February 2015; Aceite/Accepted - Março/March 2015
}

\section{Correspondência:}

Dr. Alexandre Sabino Sisnando

Fundação de Medicina Tropical Heitor Vieira Dourado (FMT-HVD)

Av. Pedro Teixeira, 25 - Dom Pedro, Manaus - AM - CEP: 69.040-000, Brazil

Tel.: +55(92)982224746

Email: alexsisnando@gmail.com

\section{INTRODUÇÃO}

Pityriasis lichenoides é uma doença cutânea rara de etiologia desconhecida, que engloba um espectro de apresentações clínicas que são caracterizadas como pityriasis lichenoides et varioliformis acuta (PLEVA) ou como pityriasis lichenoides chronica (PLC). Historicamente, o termo doença de Mucha-Habermann se refere à PLEVA, mas o termo pitiríase liquenóide se aplica de forma ampla para toda a gama de doenças, incluindo a PLC. As lesões podem sofrer involução e resolução espontâneas ao longo de semanas, ou novas lesões podem aparecer de forma recorrente, evoluindo e involuindo espontaneamente por meses ou anos após o primeiro episódio.

A apresentação clínica depende de onde o paciente cair no espectro da pityriasis lichenoides, já que as manifestações típicas concentram-se em dois polos principais:

1. Pityriasis lichenoides et varioliformis acuta (PLEVA): variante mais comum da pityriasis lichenoides, embora seja considerada doença rara que pode acometer qualquer idade, preferencialmente crianças e adultos jovens. Apresenta-se com o surgimento abrupto de múltiplas pápulas inflamatórias no tronco, nádegas e extremidades proximais. As pápulas progridem rapidamente para vesículas ou sofrem necrose central, evoluindo com crostas hemorrágicas e podendo deixar cicatrizes deprimidas. Sintomas constitucionais menores podem se fazer presentes, como febre baixa e fadiga. As lesões de PLEVA podem estar associadas com sensação de queimação e prurido. Existe também a forma febril ulceronecrótica da doença de Mucha-Habermann, que apresenta-se com sintomas constitucionais agudos, como febre alta, mal-estar intenso, vômitos, mialgias e as lesões cutâneas tendem a coalescer, exibindo necrose mais pronunciada;

2. Pityriasis lichenoides chronica (PLC): extremo subagudo do espectro, também costuma acometer crianças e adultos jovens, sem predileção racial ou de gênero. Apresenta-se como pequenas pápulas de aparência inócua, descamativas, que podem se desenvolver ao longo de dias, também com distribuição em tronco, nádegas e extremidades proximais. Cada lesão cura espontaneamente em algumas semanas, mas outras podem continuar surgindo e involuindo ao longo de meses ou anos, algumas vezes causando alteração de pigmentação. É comum o achado de pápulas descamativas em diferentes estágios, na presença de máculas hipocrômicas. Geralmente não há sintomas sistêmicos associados. ${ }^{1,2}$

\section{Caso clínico 1 - PLEVA}

Homem de 25 anos com história de febre 15 dias antes do surgimento súbito de pápulas eritematosas e vesículas, evoluindo com necrose central e crostas hemáticas/ necróticas,

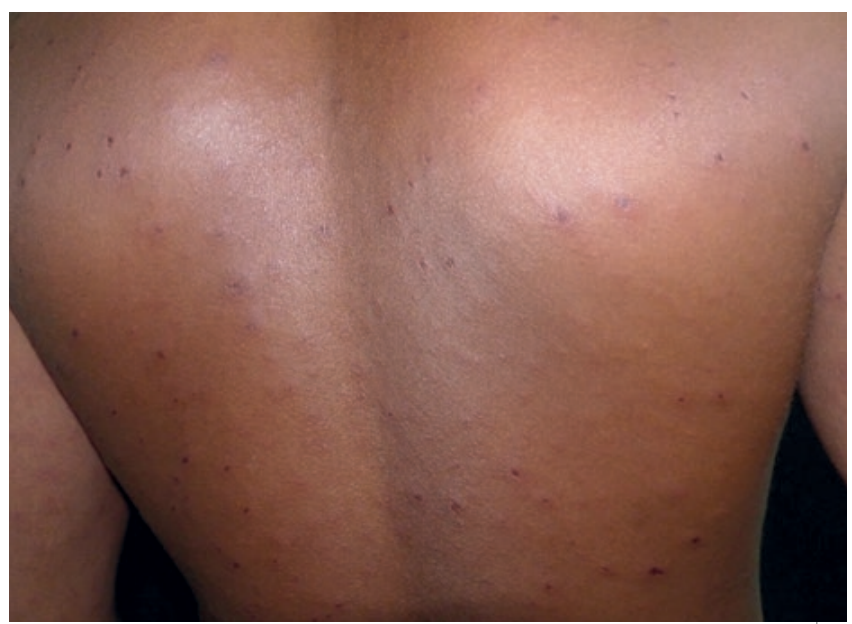

Fig 1 - Múltiplas pápulas inflamatórias no dorso, exibindo necrose central com fundo deprimido e crostas hemáticas. 


\section{Caso Clínico}

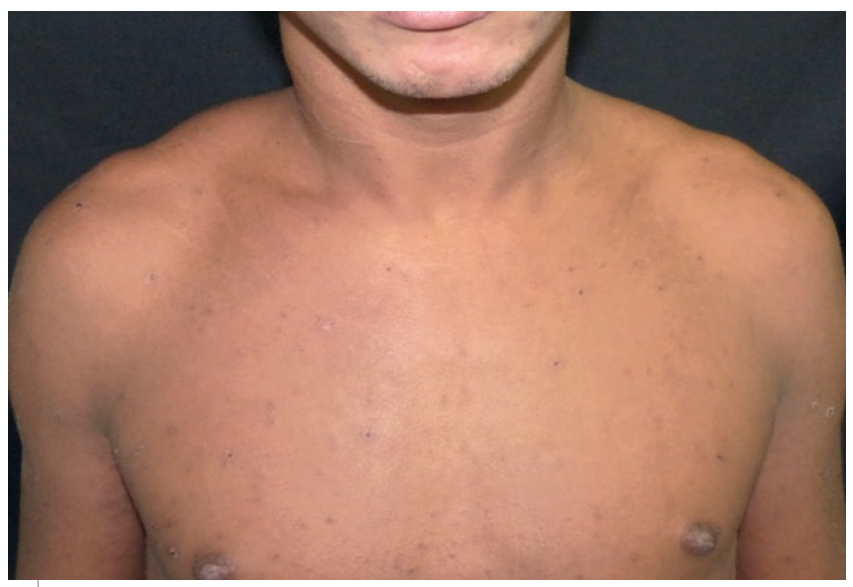

Fig 2 - Volumosa linfonodomegalia cervical à direita em paciente com várias pápulas com crosta hemática central no tórax anterior.

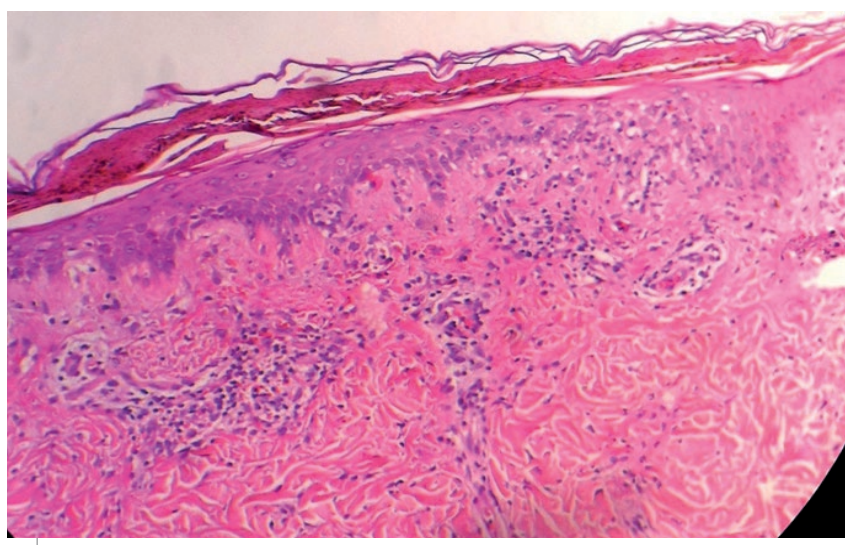

Fig 3 - Paraceratose, espongiose discreta, exocitose de linfócitos, degeneração vacuolar da camada basal e infiltrado linfohistiocitário, sem vasculite (exame anatomopatológico cutâneo).

deixando cicatrizes hipercrômicas levemente deprimidas (Fig. 1). Apresentava linfonodomegalia cervical à direita com aparecimento poucos dias antes (Fig. 2). O exame histopatológico da pele evidenciou paraceratose, espongiose discreta, exocitose de linfócitos, degeneração vacuolar da camada basal e infiltrado linfohistiocitário que se estendia da derme superficial até a derme reticular, sem vasculite (Fig. 3). $O$ histopatológico da biópsia excisional do linfonodo cervical revelou hiperplasia linfoide centrofolicular (zona de linfócitos T), sem atipias (Fig. 4). O paciente foi internado e submetido a rastreio para processos infecciosos ou neoplásicos, mas nenhuma comorbidade foi encontrada. Com a instituição de Doxiciclina $100 \mathrm{mg} 2 x /$ dia, evoluiu com melhora geral do quadro e involução das lesões após 7 dias, deixando

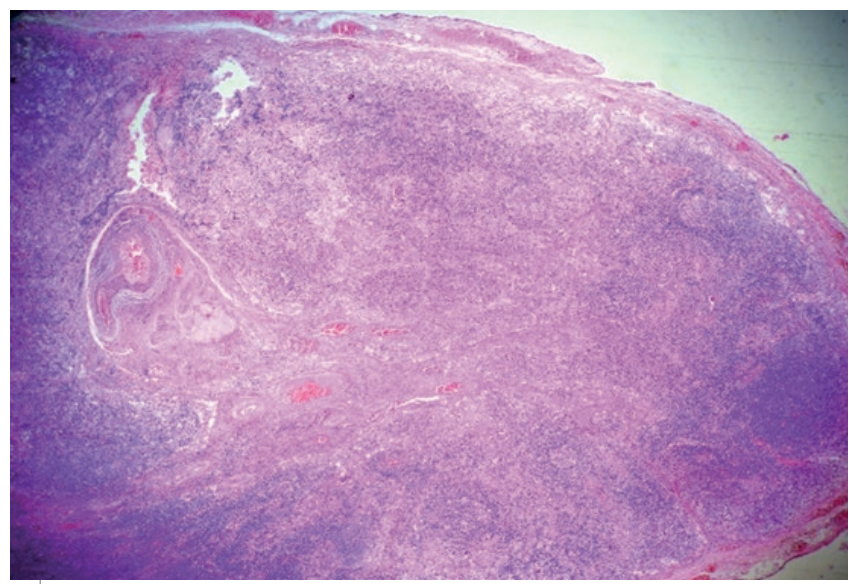

Fig 4 - Hiperplasia linfoide centrofolicular (zona de linfócitos T), sem atipias (exame anatomopatológico de linfonodo).

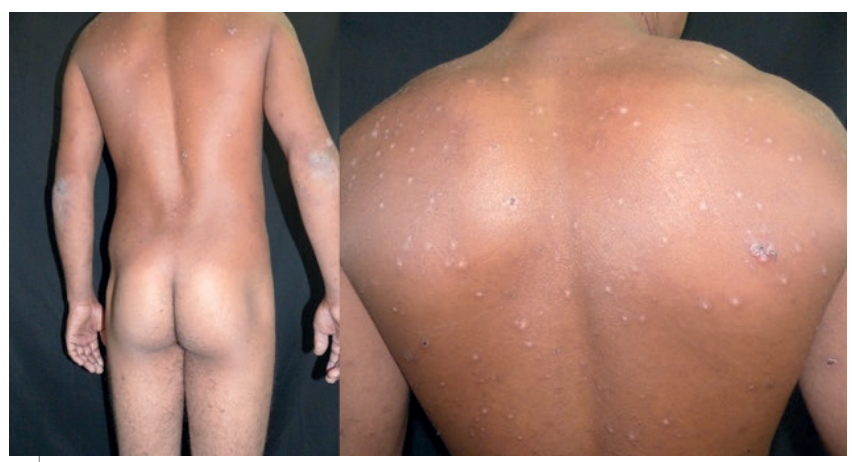

Fig 5 - Lesões de PLEVA duas semanas após início do tratamento, com hipocromia pós-inflamatória.

hipocromia residual. O tratamento foi mantido por 30 dias. $\mathrm{Na}$ região escapular direita, algumas lesões coalesceram (Fig. 5).

\section{Caso clínico 2 - PLC}

Mulher de 29 anos com quadro recorrente de lesões pruriginosas há mais de dois anos, relatando que já se submetera a diversos tratamentos (para escabiose, com anti-histamínicos, corticoides tópicos etc.), sem sucesso. Sorologias foram realizadas no início do quadro e repetidas, todas negativas. À inspeção: pápulas eritematosas com superfície levemente descamativa e máculas hipocrômicas em tronco e membros superiores. $O$ exame histopatológico das lesões no início do quadro, assim como das lesões atuais, revelou paraceratose, discreta espongiose e necrose epidérmica no centro da lesão. A paciente foi tratada com Doxiciclina $100 \mathrm{mg} /$ dia durante 3 meses, com resolução do quadro (Fig. 6). 


\section{Caso Clínico}

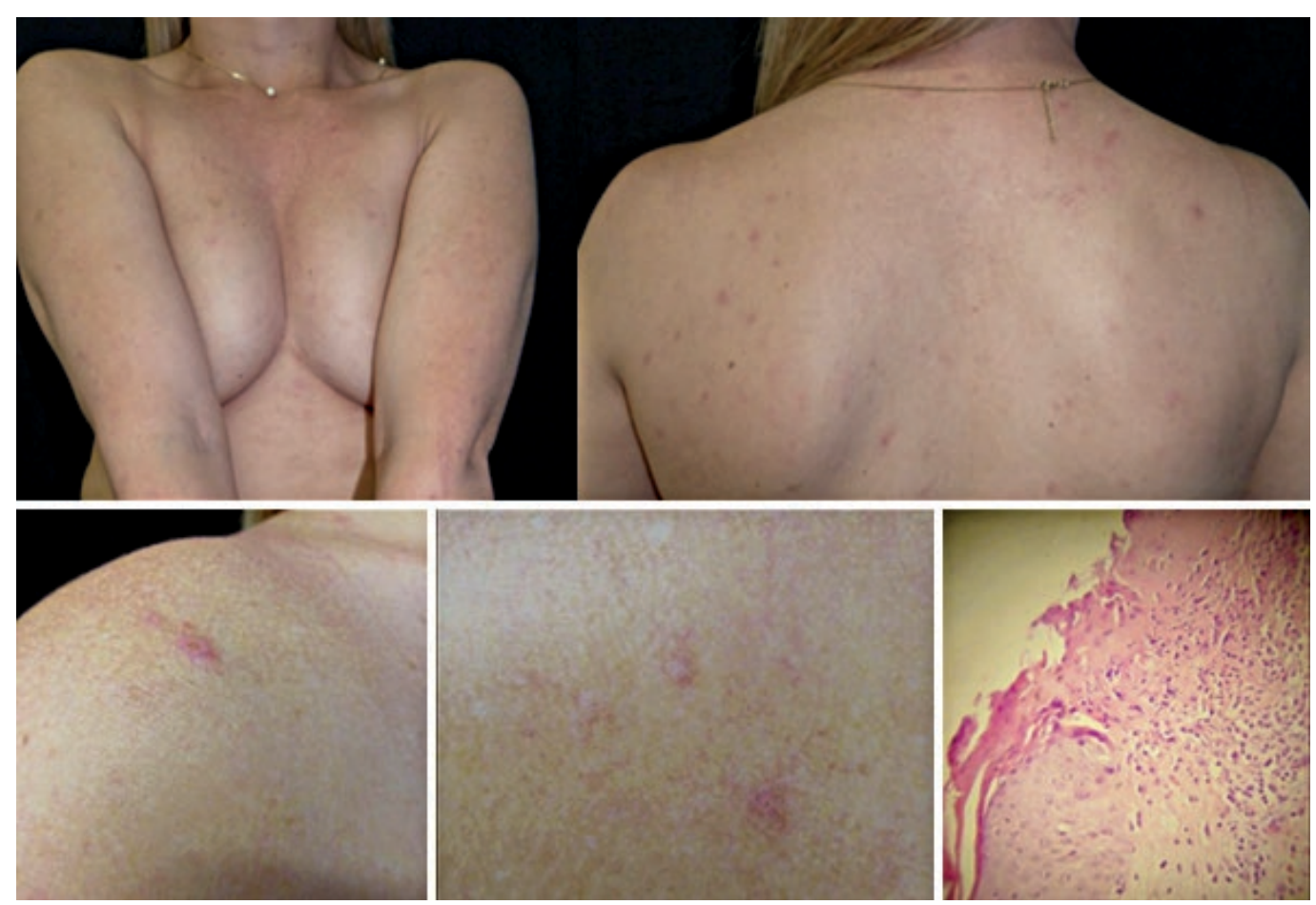

Fig 6 - Pápulas eritematosas com superfície descamativa e máculas hipocrômicas em tronco e membros superiores. Exame anatomopatológico mostra paraceratose, discreta espongiose e necrose epidérmica no centro da lesão.

\section{DISCUSSÃO}

A pitiríase liquenóide não é vasculite. Acredita-se que seja uma reação de hipersensibilidade a agentes infecciosos diversos, com proliferação clonal autolimitada de células T, em que a resposta imunológica ao clone provoca as manifestações clínicas e histopatológicas. ${ }^{2}$ A hipótese de mecanismo mediado por células é reforçada pelo achado de infiltrado de linfócitos T com fenótipo citotóxico-supressor, diminuição das células de Langerhans epidérmicas e redução da razão CD4/CD8. ${ }^{3}$ Já foram identificados linfócitos atípicos intra-epiteliais, anormalidades fenotípicas e rearranjo dos receptores do gene gama de células T (TCR-gama) pela técnica de $P C R$, além de células CD-30 (Ki-1), associadas ao linfoma de grandes células, sugerindo que a pitiríase liquenóide seja uma forma de discrasia de células T. ${ }^{4}$ Evidenciou-se também relação com HLA-B17. ${ }^{5}$

Ao exame histopatológico, as lesões típicas da PLEVA mostram paraceratose, espongiose, acantose leve a moderada, degeneração vacuolar da basal e exocitose de linfócitos e eritrócitos na epiderme; na derme papilar e reticular, geralmente se observa um denso infiltrado linfohistiocitário. Já nas de PLC, podemos encontrar queratinócitos necróticos, espongiose leve com mínima exocitose de linfócitos e alteração vacuolar da basal, além de paraceratose; na derme superficial, o infiltrado linfohistiocitário pode ser liquenoide (em faixa) ou perivascular, podendo haver poucos eritrócitos extravasados. ${ }^{1,2,5} \mathrm{~A}$ imunohistoquímica pode ajudar, mostrando que o infiltrado inflamatório é predominantemente composto de células T CD8+. Diferentemente da papulose linfomatóide, os linfócitos são CD30 negativos. ${ }^{6}$

Vários agentes infecciosos já foram implicados como desencadeantes da doença, como o parvovirus B19, ${ }^{3}$ herpesvirus $8,{ }^{2}$ toxoplasma gondii. ${ }^{7}$ Alguns autores propõem a possibilidade de um agente etiológico desconhecido. ${ }^{4}$ Desta forma, diversos tratamentos já foram relatados com sucesso, desde antibióticos como eritromicina ${ }^{8}$ até tratamentos específicos após confirmação de uma etiologia infecciosa de base, como espiramicina e cotrimoxazol ${ }^{7}$ entre outros. Quando feitos de forma empírica, podem ou não resultar em cura, sendo os de maior sucesso em relatos e estudos não controlados da literatura os macrolídeos e as tetraciclinas em doses habituais, mas por tempo prolongado, de quatro semanas ou mais. ${ }^{8,9}$

A associação de PLEVA e linfonodopatia relatada no "caso 1" não costuma ser descrita na literatura, apesar de as teorias causais sugerirem essa relação. $O$ "caso 2 " configura uma apresentação mais arrastada e recorrente de PLC. Os dois casos descritos tiveram boa resposta clínica com o tratamento proposto. 


\section{Caso Clínico}

\section{REFERÊNCIAS}

1. Fernandes NF, Rozdeba PJ, Schwartz RA, Kihiczak G, Lambert WC. Pityriasis lichenoides et varioliformis acuta: a disease spectrum. Int J Dermatol. 2010;49:257-61.

2. Kim JE, Yun WJ, Mun SK, Yoon GS, Huh J, Choi JH, et al. Pityriasis lichenoides et varioliformis acuta and pityriasis lichenoides chronica: comparison of lesional T-cell subsets and investigation of viral associations. J Cutan Pathol. 2011 ; 38:649-56.

3. Tomasini D, Tomasini CF, Cerri A, Sangalli G, Palmedo G, Hantschke $M$, et al. Pityriasis lichenoides: a cytotoxic T-ceII-mediated skin disorder. Evidence of human parvovirus B19 DNA in nine cases. J Cutan Pathol. 2004; 31:531-8.

4. Kadin, ME. T-cell clonality in Pityriasis lichenoides. Arch Dermatol. 2002;138:1089-90.
5. Foss NT, Rocha LS, Roselino AM, Donadi EA. Pitiríase liquenóide - Estudos clínicos e imunogenéticos. FMUSP Ribeirão Preto. 2000 33:32-6.

6. Hood AF, Mark EJ. Histopathologic diagnosis of pityriasis lichenoides et varioliformis acuta and its clinical correlation. Arch Dermatol.1982; 118:478-82.

7. Rongioletti F, Delmonte S, Rebora A. Pityriasis lichenoides and acquired toxoplasmosis. Int J Dermatol. 1999; 38:367-76.

8. Truhan AP, Hebert AA, Esterly NB. Pityriasis lichenoides in children: therapeutic response to erythromycin. J Am Acad Dermatol 1986 15:66-70.

9. Piamphongsant T. Tetracycline for the treatment of pityriasis lichenoides. $\mathrm{Br} J$ Dermatol. 1974;91(3): 319-22. 